\title{
Effect of steroid administration during cardiopulmonary bypass on postoperative vasoactive inotropic score
}

\author{
Kawasaki Medical School \\ Yuko Kawamoto, Yuichiro Toda, Saiko Fukunaga, Etsuko Kido, and Hideki Nakatsuka
}

Background: Steroid administration during cardiac surgery under cardiopulmonary bypass (CPB) remains controversial. It has been reported that steroid administration is effective for hemodynamic instability in septic shock refractory to a high-dose vasopressor. However, the effect of steroid administration during CPB on postoperative use of a vasoactive inotropic agent is unclear.

Objective: To investigate the effects of steroid administration during CPB on postoperative use of vasoactive agents.

Method:

$>$ The study was approved by the ethical review committee in our hospital.

$>$ Design : a retrospective, single-center cohort study

$>$ The period : from Jan I, 2014 to Dec 3I, 2015

$>$ Participants : Patients who underwent cardiac surgery under CPB

$>$ Primary outcome : vasoactive inotropic score

$>$ Statistical analyses : Student's t test, Fisher's test, multivariate analysis

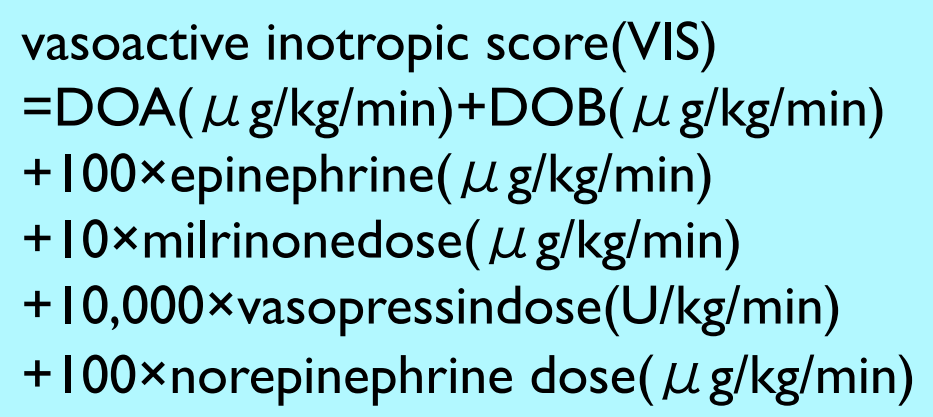

vasoactive inotropic score(VIS) $=\mathrm{DOA}(\mu \mathrm{g} / \mathrm{kg} / \mathrm{min})+\mathrm{DOB}(\mu \mathrm{g} / \mathrm{kg} / \mathrm{min})$

$+100 \times$ epinephrine $(\mu \mathrm{g} / \mathrm{kg} / \mathrm{min})$

$+10 \times$ milrinonedose $(\mu \mathrm{g} / \mathrm{kg} / \mathrm{min})$

$+10,000 \times$ vasopressindose $(\mathrm{U} / \mathrm{kg} / \mathrm{min})$

$+100 \times$ norepinephrine dose $(\mu \mathrm{g} / \mathrm{kg} / \mathrm{min})$

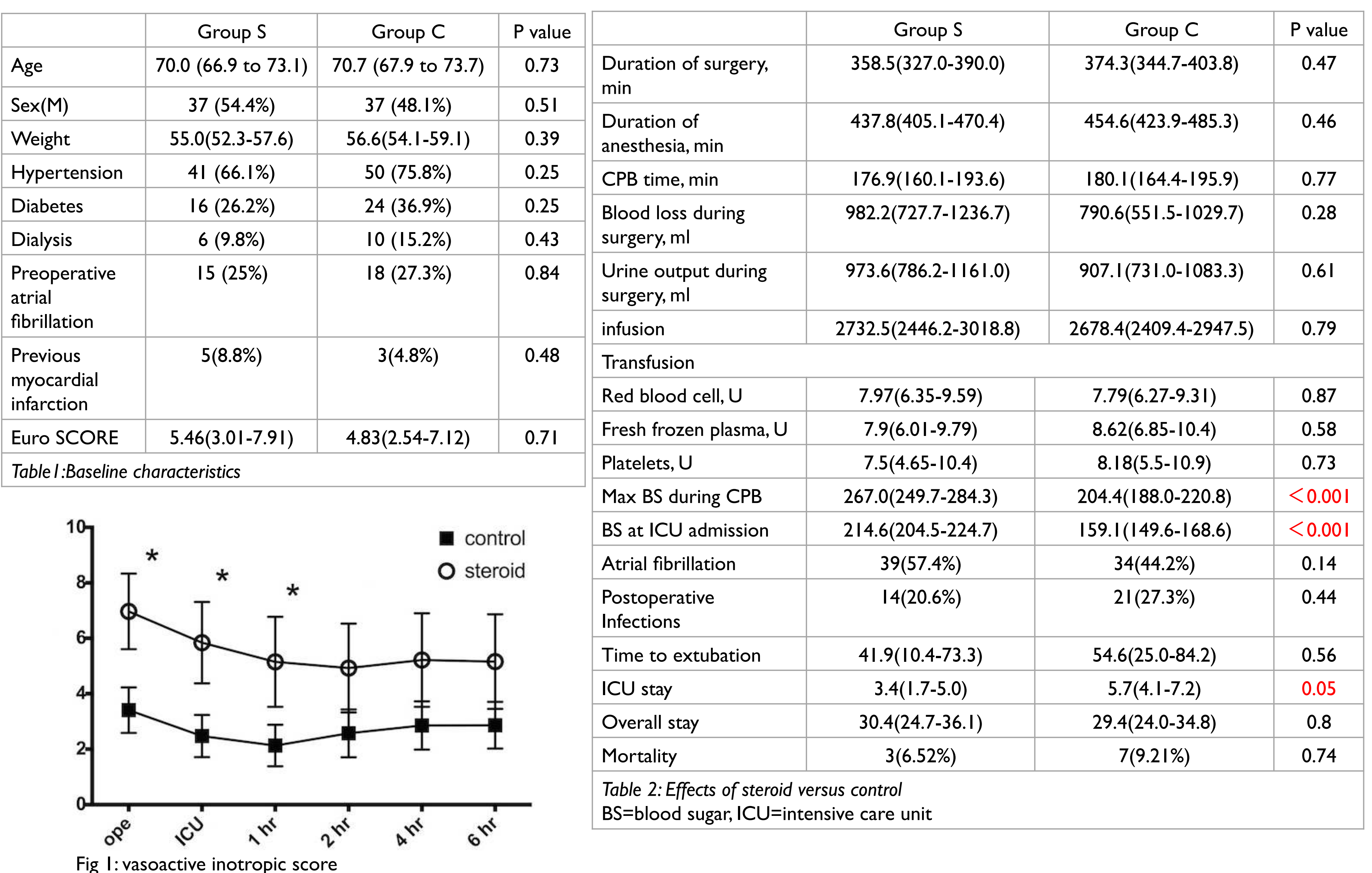

【Result】

Fig I: vasoactive inotropic score

There were 68 patients (Group S) who received a steroid during CPB and 77 patients (Group C) who did not.

The characteristics of patients were not different between the two groups (table I).VIS was significantly higher in Group $S$ than in Group C (Fig I). Max BS during CPB and BS at ICU admission was significantly higher in Group S than in Group C. There was no difference in incidence of arterial fibrillation or postoperative infections between the two groups. ICU stay was significantly longer in Group C than in Group S.

【Conclusion】

Doses of vasoactive agents were not reduced by steroid administration during cardiopulmonary bypass.

【Reference】

intensive care med 2012, 38; 1184-1190

Richard P, PJ Devereaux, Kevin H. Methylprednisolone in patients undergoing cardiopulmonary bypass 